\title{
Modification of Eclipse simulator for microbial enhanced oil recovery
}

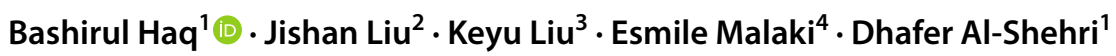

Received: 28 July 2018 / Accepted: 8 January 2019 / Published online: 22 February 2019

(c) The Author(s) 2019

\begin{abstract}
Many widely used reservoir simulators include an EOR option, but there is no feature available in a commercial simulator in the oil industry that simulates microbial enhanced oil recovery (MEOR) process. Eclipse, one of the popular reservoir simulators, does not have this option. In this study the Eclipse reservoir simulator has been modified and used to simulate MEOR core-flooding experiments. The combined effects on oil recovery of anionic surfactants and alcohol, nonionic surfactants and alcohol, and anionic and nonionic surfactants blended with alcohol are examined. A commercial Eclipse simulator was modified to add the option to simulate a MEOR process as this was not available. The modified simulator was used to simulate three core-flood experiments with three formulations. The JF-2 bio-surfactant and butanol solution core-flood test was simulated. The result was slightly higher than the experimental result but compared reasonably well. The simulated tertiary and total oil recoveries of the APG and butanol solution were similar to the experimental values: the simulated TOR and total recovery were $41 \%$ and $81 \%$, respectively, while the core-flooding TOR and total recovery were $41 \%$ and $82 \%$. The APG, bio-surfactant and butanol combination core-flood experiment, when simulated, produced an oil recovery curve that was a reasonable match with the experimental curve.
\end{abstract}

Keywords Simulation $\cdot$ Core flood $\cdot$ MEOR $\cdot$ Green surfactant $\cdot$ GEOR

\section{Introduction}

Using reservoir simulators to predict and understand the processes taking place during chemical flooding is currently of renewed interest to the industry given current oil prices, which have greatly increased the interest in enhanced oil recovery. As with other simulators, chemical flooding simulators are often used to history match and understand the results of core floods in field performance.

The simulation of core flood was used in this study to understand, optimize, interpret, and design the green enhanced oil recovery (GEOR) flooding process. GEOR is

Bashirul Haq

bhaq@kfupm.edu.sa; bhaq225@gmail.com

1 Department of Petroleum Engineering, King Fahd University of Petroleum and Minerals (KFUPM), Dhahran, Saudi Arabia

2 School of Mechanical and Chemical Engineering, The University of Western Australia, Perth, Australia

3 School of Geosciences, China University of Petroleum (East China), Qingdao 266580, Shandong, China

4 Schlumberger SIS, Brisbane, Australia a chemical EOR involving the injection of specific green chemicals (surfactants/alcohols/polymers) that effectively displace oil because of their phase-behavior properties, which decrease the IFT between the displacing liquid and the oil. In this process, the primary displacing liquid slug is a complex chemical system called a micellar solution, containing green surfactants, co-surfactants, oil, electrolytes, and water. The surfactant slug is relatively small, typically $10 \%$ PV (Green and Willhite 1998). It may be followed by a mobility buffer, a solution that contains polymer at a concentration of a few $100 \mathrm{mg} / \mathrm{l}$. This polymer solution is often graded in concentration, with the polymer becoming more dilute as more of the solution is injected. The total volume of the polymer solution is typically about $1 \mathrm{PV}$ (Green and Willhite 1998).

Three formulations of green surfactants were simulated, and the results were used to investigate the effectiveness of each surfactant mixture. Three core models for three formulations were simulated to examine the relationship between oil recovery and injected surfactant solutions. In all cases, fresh water was first injected into the core model and then surfactant solutions were injected to see the effect of secondary and tertiary recoveries. The JF-2 bio-surfactant from 
anionic green surfactants with butanol as a co-surfactant was modeled in the first formulation. The second formulation was the nonionic surfactant APG with butanol. The final one was a mixture of anionic and nonionic surfactants with a co-surfactant, in this case APG and JF-2 bio-surfactant blended with butanol.

The modifications to the Eclipse simulator were: (a) the combined effect of surfactant and alcohol, anionic and nonionic surfactants with alcohol on oil recovery, and (b) the effect of volumetric sweep efficiency on recovery.

\section{Background to the study}

In the past 30 years, chemical flooding simulators have become more and more complex. The need for accurate chemical flooding prediction has become more important as enhanced oil recovery projects have received more attention. Nelson (1983), Todd and Chase (1979), and Dongu et al. (1984), were among the first to publish papers on chemical flooding simulators.

Eclipse was developed by Exploration Consulted Limited (ECL) in the late 1970s. Its first commercial release was announced at the SPE in San Francisco, in 1983. Eclipse 100 is a black oil simulator, which computes the flow of fluids such as oil, water, and gas through porous media in reservoirs on the assumption that the oil and gas are homogeneous fluids and that the oil is allowed to dissolve in the gas and vice versa. The reservoir is discretised into grid blocks and the flow is computed using Darcy's law. In the early years (Gjerde et al. 1988) proposed parallelization in the linear solver of black oil simulators based on isolated geologic structures. They succeeded in creating parallelized sections that took into account the possible number of phases present in each reservoir; in the old version, if three phases were present in a reservoir, then all reservoirs were treated as three phase. Gjerde et al. (1988) offered a model whereby if any reservoir had two phases, it could be treated as a two-phase reservoir. This reduced the number of equations to be solved for the two-phase case by a factor of four-ninths.

$\mathrm{Yu}$ et al. (1998) used Eclipse to simulate core-flood experiments and to match simulated data with experimental results. The core-flood experiments were performed using live pre-equilibrated oil and gas phases at reservoir conditions by separating liquid samples and excess gas. The core-flood conditions were designed prior to the physical experimental, using the reservoir simulator. The basis for history matching was the $\mathrm{CT}$ in situ saturation measurements of oil and gas in six cross sections along the length axis of the core versus pore volume (PV) of the equilibrium gas injected; oil and gas production volumes versus PV injected; and the differential pressure recordings across the core during the injection experiments. The results identified the most important dynamic reservoir parameters and characteristics that controlled the recovery mechanism during each displacement sequence of the experiments. Yu et al. (1998) also investigated hysteresis functions in the two-phase gas-oil injection sequences.

Kumur and Shrivastava (2000) studied the effect of gas saturation on oil's relative permeability and mobility ratio using Stone I, II, and Eclipse default methods. They found that use of Stone II caused serious problems when it created immobile oil saturation around the prolific producer wells; as a result the relative permeability of the oil came to zero. The Eclipse default method gave significantly higher values of relative permeability and very low values of mobility ratio in comparison with both Stone I and Stone II.

Salimi and Bruining (2008) carried out simulations of waterflooding in fractured media and formulated a numerical 3D model for the boundary condition (BC) approach. The results from this model were compared with those from Eclipse, which was based on the Warren and Root (WR) approach of an empirical transfer function between the fracture and matrix block. The comparison showed that the cumulative oil and water production for both the Homogenized model and Eclipse were the same at lower Péclet numbers, but at higher Péclet numbers the Homogenized model predicted a higher oil production in the early stages than Eclipse. Afterwards, the predicted rate of oil production of Eclipse became higher than the rate of oil production predicted by the Homogenized model, and gradually the cumulative oil and water production of Eclipse reached the value of the cumulative oil and water production of the Homogenized model. One of the most important reasons for the discrepancy between the Homogenized and Eclipse models was that three-dimensional matrix block subgridding was not available in Eclipse.

The skin factor in horizontal injection wells caused by the injection of particulated water monotonically increases with time. Bedrikovetsky et al. (2009) investigated the effects of injected water quality on waterflooding using the Eclipse 100 reservoir simulator and found that the option of water injection with a constant skin factor was already available in the Eclipse model, but it was not able to calculate variable skin factors. They designed an analytical model for injectivity decline, accounting for particle capture and a low permeability external filter cake formation in the Eclipse simulator, to examine the effect of raw water injection on sweep efficiency during waterflooding. It was shown that sweep efficiency in a heterogeneous formation can increase by up to $5 \%$, compared with clean water injection, after one pore volume injected.

Tiamiyu and Boukadi (2011) performed a simulation study of surfactant and de-emulsifier blend additives in steam flooding as an EOR technique in heavy oil reservoirs, using Eclipse. This study concluded that surfactant-added 
steam flooding could not be simulated with the available simulator as it had no option to examine combines effects; however, the simulation of core-flooding runs for water, surfactant solution, and steam flooding were successful and confirmed the validity, accuracy, and applicability of laboratory results.

Shabani-Afrapoli et al. (2012) tried to simulate microbial improved oil recovery (MIOR) core flooding using Eclipse and found that there was no option to examine the combined effect of bio-surfactants and bio-alcohol; in MIOR, bio-products work in combination to increase oil recovery. They concluded that Eclipse 100 (version 2009) was not a powerful enough tool to simulate MIOR because the bacterial effect on reservoir properties, particularly relative permeability, capillary pressure, and wettability changes, were not expressible in this simulator.

It was found that options to measure the combined effect of surfactant and alcohol, and of oil recovery efficiency, needed to be added to Eclipse to simulate GEOR.

\section{Model description}

The core-flooding model is a batch process. In Eclipse, the model is created as an ASCII text file, usually specified as: *.DATA (Schlumberger 2017). This file contains a complete description of the model and a collection of keywords and comments. Each keyword has a specific syntax, although many keywords have similar or identical syntax. The data file is divided into sections by a few specific keywords: RUNSPEC, GRID, EDIT, PROS, REGIONS, SOLUTION, SUMMARY, and SCHEDULE. The model reads the input data file section by section and processes each section in turn as it is read. Various data and consistency cheeks are made before proceeding to the next section. The last section is exceptional because it specifies time-dependent data and is not read and processed as a whole; instead, the keywords are processed in the order they are presented in the data file.

The RUNSPEC section allocates memory for general model characteristics. Although the model is dynamically dimensioned and reserves as much memory as is required for the simulation as a whole, different kinds of information in the simulation require varying amounts of memory.

The simulation grid geometry and properties are processed into a form more convenient for calculation in the GRID section. For each cell, the model calculates the pore volume, transmissibility in three dimensions and cell centre depth, and creates connections to other cells to or from which fluid may flow. The EDIT section modifies the processed GRID data if required.

The rock and fluid properties are specified in the PROPS section. The term "fluid property" refers to a set of input tables that effectively defines the phase behavior of each phase. The term "rock property" refers to sets of input tables of relative permeability and capillary pressure versus saturation. Effectively, this defines the connect, critical, and maximum saturation of each phase, supplies information for defining the transition zone, and defines the conditions of flow of phases relative to one another. This strongly affects the ratios of produced phases, that is, water cuts and gas oil ratios (GORs). The REGIONS section subdivides the reservoir.

In the SOLUTION section, the initial conditions are defined, often by specifying the oil-water contact (OWC) and or gas oil contact (GOC) depths and the pressure at a known depth. The model uses this information in conjunction with much of the information from previous stages to calculate the initial hydrostatic pressure gradients in each zone of the core (reservoir) and allocate the initial saturation of each phase in every grid cell prior to production and injection. This is called initialization.

The SCHEDULE section of the data file is where simulation actually begins. Wells are drilled, perforated and completed, production and injection targets are set up, wells are opened and fluids flow through the reservoir (core), driven by the wells.

The outputs of the simulation and their progress at dates during the simulation are defined in the SUMMARY section. Once the run has finished, the outputs are examined using text editors and post-processors of various degrees of sophistication.

\section{Relationship between section and equation}

The flow equation relates different sections in the data file; it is called a well model in simulation. The simulator flow equation is derived from Darcy's law and material balance equation, and solved for each cell and each time-step. In simulation, flow is simulated from one grid block to the next, from a grid block to the well completion, and within the injection and production wells. Fluid flow in each cell in the core is the product of the transmissibility of the rock, the mobility of the fluid and the potential difference between injection and production wells. Transmissibility of the rock is described in geometry, and properties of rock in the GRID and EDIT sections. Mobility is a fluid property. All data and necessary information are put in the PROS, REGIONS, and SOLUTION sections. Potential differences between wells are explained in the SCHEDULE section. Figure 1 below shows how the sections map to the equations (Schlumberger 2017).

\section{Surfactant model}

The distribution of injected surfactant is modeled by solving a conservation equation for surfactant in the water phase. The surfactant concentrations are updated fully implicitly at

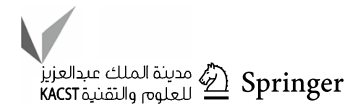




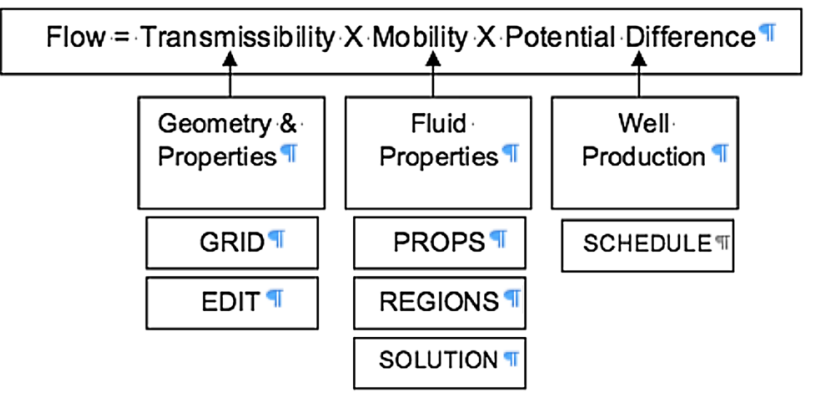

Fig. 1 Relationship between section and equation

the end of each time-step after the oil, water, and gas flows have been computed. The surfactant is assumed to exist only in the water phase, and the input to the core as a concentration at a water injector (in the WSURFACT keyword). The limitation of surfactant model in Eclipse are: (1) it does not include the detailed chemistry of surfactant process and models only the important features of a surfactant flood on a full field basis and (2) it does not model the phase behavior of the surfactant (Schlumberger 2017).

Equations (1-8) in surfactant model depend either on surfactant concentration or IFT. These equations are applied to calculate the key parameters such as capillary pressure, relative permeability, capillary number, water viscosity, and surfactant adsorption using tabled values. There are five different tables in the surfactant input file. Among these input, the surfactant concentration with IFT, viscosity and adsorption tables are the most influential. The IFT versus surfactant concentration table is inserted as in an input parameter and this table is used to calculated capillary pressure, relative permeability, capillary number, water viscosity, and surfactant adsorption. The study uses constant values of viscosity, and adsorption to examine the effect of IFT values with varying surfactant and alcohol concentrations. As surfactant model in eclipse does not include chemical reaction and phase behavior of surfactant, it gives most likely acceptable results when surfactant and co-surfactant solution concentration and IFT table are given an input. To get good oil recovery, it would be better to add surfactant losses in designing surfactant flood system by adding more surfactant to make sure the operating surfactant concentration is above the CMC.

Working process and key equations of the surfactant model are described below.

\section{Working process}

Step 1 The interfacial tension (IFT) table as function of surfactant concentration is inserted in the data file. Then, capillary number is calculated as a function of the IFT using Eq. (1).
Step 2 Surfactant relative permeability data are added as input file for immiscible interaction between oil and water. When surfactant is added to the system, mixing between water and chemical takes place and relative permeability data for the miscible phase is calculated from the given immiscible relative permeability data. These calculated data are used by the grid blocks that contain surfactants. The relative permeability model allows a transition from immiscible relative permeability curves at low capillary number to miscible relative permeability curve at high capillary number. The interpolation parameter $F_{\mathrm{kr}}$ is the tabulated function of the logarithm (base 10) of the capillary number $\left(N_{\mathrm{c}}\right)$, is presented in Eq. (4) and defined in SURFCAPD keyword (Schlumberger 2017).

Step 3 Water-oil capillary pressure is reduced as the surfactant concentration is increased during the flood and the capillary pressure is calculated by the Eq. (5).

Step 4 Water viscosity is changed when the surfactant is mixed with water. It is also a function of surfactant concentration, and is calculated by the Eq. (6).

Step 5 The surfactant solution adsorbs onto the core. The wettability of the rock changes as a function of the amount of surfactant adsorbed. The quantity of absorbed surfactant is defined as a function of surrounding surfactant concentration. The absorbed mass is defined by Eq. (8).

\section{Main equations}

\section{Capillary number}

The capillary number is a dimensionless group that measures the ratio of viscous forces to capillary forces. The capillary number is given by:

$N_{\mathrm{c}}=\frac{|K \cdot \operatorname{grad} P|}{\mathrm{ST}} C_{\text {unit }}$,

$|K \cdot \operatorname{grad} P|=\sqrt{\left(K_{x} \cdot \operatorname{grad} P_{x}\right)^{2}+\left(K_{y} \cdot \operatorname{grad} P_{y}\right)^{2}+\left(K_{z} \cdot \operatorname{grad} P_{z}\right)^{2}}$,

where $K=$ permeability, $P=$ potential, $\mathrm{ST}=\mathrm{IFT}, C_{\text {unit }}=$ conversion factor depending on the units used.

For cell $i$

$$
\begin{aligned}
K_{x} \cdot \operatorname{grad} P_{x}= & 0.5\left[\left(\frac{K_{x}}{D_{x}}\right)_{i-1, i} \cdot\left(P_{i}-P_{i-1}\right)\right. \\
& \left.+\left(\frac{K_{x}}{D_{x}}\right)_{i, i+1} \cdot\left(P_{i+1}-P_{i}\right)\right],
\end{aligned}
$$

and similarly for the $y$ and $z$ directions.

The $K / D$ value is calculated in an analogous manner to the transmissibility and depends on how the geometry was specified. 
The surface tension is a tabulated function of the surfactant concentration.

\section{Relative permeability}

The relative permeability model is essentially a transition from immiscible relative permeability curves at low capillary number to miscible relative permeability curves at high capillary number. A table is supplied that describes the transition as function of $\log 10$ (capillary number). The keyword SURFCAPD is used to define an interpolation parameter $F_{\mathrm{kr}}$ as a tabulated function of $\log _{10} N_{\mathrm{c}}$. The weighting function $F$ can be expressed as:

$F=F_{\text {kr }}\left(\log _{10} N_{\mathrm{c}}\right)$.

The relative permeability used at a value of the miscibility function between the two extremes is calculated in two steps. The first end points of the curve are interpolated and both the immiscible and the miscible curves are scaled to honor these points. Stone II relative permeability model is presented in "Appendix A."

\section{Capillary pressure}

The water-oil capillary pressure will reduce as the concentration of surfactant increases; indeed it is the reduction in the water capillary pressure that gives rise to the reduction in the residual oil saturation. The oil-water capillary pressure is taken as:

$P_{\text {cow }}=P_{\text {cow }}\left(S_{\mathrm{w}}\right) \frac{\mathrm{ST}\left(C_{\text {surf }}\right)}{\mathrm{ST}\left(C_{\text {surf }}=0\right)}$,

where $\operatorname{ST}\left(C_{\text {surf }}\right)=$ surface tension at the present surfactant concentration, $\operatorname{ST}\left(C_{\text {surf }}=0\right)=$ surface tension at the zero concentration, $P_{\text {cow }}\left(S_{\mathrm{w}}\right)=$ capillary pressure from the immiscible curves initially scaled to the interpolated end points calculated in the relative permeability model.

\section{Water PVT properties}

The surfactant modifies the viscosity of the pure or salted water input using the PVTW or PVTSALT keyword, respectively. The surfactant viscosity input as a function of surfactant concentration using the SURFVISE keyword is used to calculate the water-surfactant solution viscosity as follows:

$\mu_{\mathrm{ws}}\left(C_{\text {surf }}, P\right)=\mu_{\mathrm{w}}(P) \frac{\mu_{\text {surf }}\left(C_{\text {surf }}\right)}{\mu_{\mathrm{w}}\left(P_{\text {ref }}\right)}$.

If the Brine option is active, Eq. (6) becomes a function of salt concentration $C_{\text {salt }}$ as well:

$\mu_{\mathrm{ws}}\left(C_{\text {surf }}, P, C_{\text {salt }}\right)=\mu_{\mathrm{w}}\left(P, C_{\text {salt }}\right) \frac{\mu_{\text {surf }}\left(C_{\text {surf }}\right)}{\mu_{\mathrm{w}}\left(P_{\text {ref }}, C_{\text {salt-ref }}\right)}$, where $\mu_{\mathrm{ws}}=$ viscosity of the water-surfactant mixture, $\mu_{\mathrm{w}}=$ viscosity from the PVTW or PVTSALT keywords, $\mu_{\text {surf }}=$ viscosity from the SURFVISC keyword, $P_{\text {ref }}=$ reference pressure in the PVTW or PVTSALT keywords, $C_{\text {surf }}=$ surfactant concentration, $C_{\text {salt }}=$ reference salt concentration in the PVTSALT keywords.

\section{Adsorption}

The adsorption of a surfactant is assumed to be instantaneous, and the quality of adsorption is a function of the surrounding surfactant concentration. Data are supplied as an adsorption isotherm as a function of surfactant concentration in the SURFADS keyword.

The quantity of surfactant adsorption on the rock is given by

$M_{\mathrm{AS}}=P V_{\text {cell }} \cdot \frac{1-\phi}{\phi} \cdot \rho_{\text {mas }} \cdot C A\left(C_{\text {surf }}\right)$,

where $M_{\mathrm{AS}}=$ mass of adsorbed surfactant, $\mathrm{PV}_{\text {cell }}=$ pore volume of the cell, $\varnothing=$ porosity, $\rho_{\text {mas }}=$ mass density of the rock in the SURFROCK keyword, $\operatorname{CA}\left(C_{\text {surf }}\right)=$ adsorption isotherm as a function of local surfactant concentration in solution.

\section{Modification of Eclipse}

The Eclipse simulator was modified to enable it to simulate MEOR and GEOR, as it did not have these options. Two modifications were made: adding the IFT table as a function of the surfactant and alcohol concentration, to replace the existing data file that contained only surfactant concentration; and adding a volumetric sweep efficiency (Ev) term in Eclipse's field oil efficiency (FOE) equation.

\section{Modification one: addition of IFT table}

\section{The existing Eclipse system}

Conventionally in Eclipse, surfactant-water solution injected into the core and surfactant concentrations are solved by conservation equations in the water phase. The IFT table as a function of surfactant concentration is looked up, then the capillary number is calculated as a function of IFT. The relative permeability of the oil and water phase is interpolated as a function of the capillary number. Water-oil capillary pressure is reduced as a function of the IFT of the surfactant concentration. After that, water viscosity is changed as a function of surfactant concentration, and the surfactant solution 
adsorbs onto the core. Finally, the wettability of the rock changes as a function of the amount of surfactant adsorbed.

\section{Reason for modification}

In MEOR, microbes produce bio-products such as biosurfactant and bio-alcohol. These bio-products in combination produce in a solution called nutrient. A surfactant-alcohol solution reduces IFT and increases oil recovery. Similarly, in GEOR a surfactant and alcohol mix is used to reduce IFT and enhance oil production. For this reason, in GEOR green surfactants, alcohol, and water in solution are used in place of a surfactant-water solution.

\section{Introducing the modification}

First, green surfactant, alcohol, and water are mixed into solution and injected into the core; then surfactant and alcohol mixture concentration is solved by conservation equation. The IFT table is made a function of the surfactant-alcohol concentration, and the capillary number is calculated as function of IFT. The relative permeability of the oil and water phase is interpolated as a function of the capillary number. Water-oil capillary pressure is reduced as a function of IFT of surfactant-alcohol or surfactant-mixture concentration. After that water viscosity is changed as a function of surfactant-alcohol mixture concentration, and surfactant-alcohol solution adsorbs onto core. Finally, the wettability of the rock changes as a function of the amount of surfactant-alcohol solution adsorbed.

\section{Modification two: addition of volumetric sweep efficiency $\left(E_{\mathrm{v}}\right)$}

\section{The exiting Eclipse field oil efficiency (FOE) equation}

The oil in place within a grid block is expressed in Eclipse (Schlumberger 2017) as follows:

Oil in place $(\mathrm{OIP})=\frac{\mathrm{PV} \times S_{\mathrm{O}}}{B_{\mathrm{O}}}$,

where PV = pore volume, $S_{\mathrm{o}}=$ oil saturation $=1-S_{\mathrm{w}}-S_{\mathrm{g}}$, $S_{\mathrm{w}}$ - water saturation, $S_{\mathrm{g}}-$ gas saturation $=0, B_{\mathrm{o}}-$ oil formation volume factor.

Oil recovery efficiency is calculated as oil efficiency (Schlumberger 2017). Field oil efficiency is expressed as the keyword FOE and calculated using the equation below:

Field oil efficiency $(\mathrm{FOE})=\frac{\mathrm{OIP}_{\text {initial }}-\mathrm{OIP}_{\text {now }}}{\mathrm{OIP}_{\text {initial }}}$, where $\mathrm{OIP}_{\text {initial }}=$ oil in place at beginning, $\mathrm{OIP}_{\text {now }}=$ oil in place at present.

Equations (9) and (10) express oil in place and field oil efficiency, respectively. Equation (1) can be written at initial and final (after water and/or surfactant flood in core-flood experiment) stages as follows:

$(\mathrm{OIP})_{\text {initial }}=\frac{\mathrm{PV} \times S_{\mathrm{oi}}}{B_{\mathrm{oi}}}$

$(\mathrm{OIP})_{\text {final (after water/surfac flood })}=\frac{\mathrm{PV} \times S_{\mathrm{o}}}{B_{\mathrm{o}}}$,

where $\mathrm{PV}=$ total pore volume of the core, $S_{\mathrm{oi}}=$ oil saturation at initial condition, $S_{\mathrm{o}}=$ oil saturation at final (after water/ surfactant flood), $B_{\mathrm{oi}}=$ oil formation volume factor at initial condition, $B_{\mathrm{o}}=$ oil formation volume factor at present (after water/surfactant flood).

Putting the value of Eqs. (11) and (12) in Eq. (9), we get

Field oil efficiency (FOE) $=\frac{\frac{\mathrm{PV} \times S_{\mathrm{oi}}}{B_{\mathrm{oi}}}-\frac{\mathrm{PV} \times S_{\mathrm{o}}}{B_{\mathrm{o}}}}{\frac{P V \times S_{\mathrm{oi}}}{B_{\mathrm{oi}}}}=\frac{\frac{S_{\mathrm{oi}}}{B_{\mathrm{oi}}}-\frac{S_{\mathrm{o}}}{B_{\mathrm{o}}}}{\frac{S_{\mathrm{oi}}}{B_{\mathrm{oi}}}}$.

Assuming the constant a constant $B_{\mathrm{o}}$ during the flooding life, as pressure and temperature remain constant and used oil is dead oil. So $B_{\mathrm{oi}}$ is equal to $B_{\mathrm{o}}$.

The final form of Eq. (13) becomes

$\mathrm{FOE}=\frac{S_{\mathrm{oi}}-S_{\mathrm{o}}}{S_{\mathrm{oi}}}$

Equation (14) is the final form of FOE equation which is used to calculated field oil recovery efficiency in Eclipse and it does not include volumetric sweep efficiency.

\section{The need for modification}

Volumetric sweep efficiency is the fraction of the floodable portion of the reservoir swept or contacted by water. It is the product of the areal $\left(E_{\mathrm{A}}\right)$ and vertical $\left(E_{\mathrm{V}}\right)$ sweep $\left(E_{\mathrm{VW}}=E_{\mathrm{A}} \times E_{\mathrm{V}}\right)$. It is useful to compute the volumetric sweep efficiency of the injected water, as this assists in the management and calculation of future waterflood recovery potential in a mature waterflood. Volumetric sweep efficiency is important because it defines the fraction of the reservoir swept by the injected water (Cob and Marek 1997).

The volumetric sweep efficiency of $E_{\mathrm{VW}}$ represents the fraction of the reservoir contacted by the injected water. If the water injection wells are also used as EOR injectors, the EOR injection is likely to sweep the same volume swept by the water. Conversely, $\left(1-E_{\mathrm{vw}}\right)$ defines that portion of the reservoir not swept by the injected water, and so identifies 
that portion of the reservoir where recoverable waterflood oil volumes are likely to exist (Cob and Marek 1997). Mathematical development of volumetric sweep efficiency is discussed in "Appendix A".

\section{Introducing the modification}

Oil recovery by surfactant process can be approximated by the application of a simple material balance (Green and Willhite 1998). Because a favorable mobility ratio is maintained during the process, volumetric sweep efficiency is assumed to be the same as for a waterflood preceding the surfactant process. A constant oil formation volume factor is assumed as pressure and temperature do not change during flood life.

Oil recovery at the end of waterflood is given by

$N_{\mathrm{p}}=\frac{A \times h \times \varphi\left(S_{\mathrm{oi}}-S_{\mathrm{orw}}\right)}{5.615 \times B_{\mathrm{o}}} \times E_{\mathrm{vw}}$.

Oil recovery at the end of surfactant flood is given by

$N_{\mathrm{p}}=\frac{A \times h \times \varphi\left(S_{\text {orw }}-S_{\text {orc }}\right)}{5.615 \times B_{\mathrm{o}}} \times E_{\mathrm{vw}}$.

The combined oil recovery at the end of water and surfactant flood is (assuming resaturation of oil in the unswept region):

$N_{\mathrm{p}}=\frac{A \times h \times \varphi\left(S_{\mathrm{oi}}-S_{\mathrm{orc}}\right)}{5.615 \times B_{\mathrm{o}}} \times E_{\mathrm{vw}}$.

Original oil in place is given by

$N=\frac{A \times h \times \varphi \times\left(S_{\mathrm{oi}}\right)}{5.615 \times B_{\mathrm{o}}}$,

where $N_{\mathrm{p}}=$ oil recovered in process, $\mathrm{STB}, N=$ original oil in place, $\mathrm{STB}, A=$ pattern area, $\mathrm{ft} 2, h=$ reservoir thickness, $\mathrm{ft}, \varnothing=$ porosity, $S_{\text {orw }}=$ residual oil saturation at termination of waterflood, $S_{\text {orc }}=$ residual oil saturation at termination of chemical flood, $S_{\mathrm{oi}}=$ initial oil saturation, $E_{\mathrm{vw}}=$ volumetric sweep efficiency of waterflood preceding chemical flood, $B_{\mathrm{o}}=$ oil formation volume factor, RB/STB.

Oil recovery efficiency (ORE) after water and surfactant flood is given by

$\frac{N_{\mathrm{P}}}{N}=\frac{\frac{A \times h \times \varphi\left(S_{\mathrm{oi}}-S_{\mathrm{orc}}\right)}{5.615 B_{\mathrm{o}}} \times E_{\mathrm{vw}}}{\frac{A \times h \times \varphi \times\left(S_{\mathrm{oi}}\right)}{5.615 B_{\mathrm{o}}}}=\frac{\left(S_{\mathrm{oi}}-S_{\mathrm{orc}}\right)}{\left(S_{\mathrm{oi}}\right)} \times E_{\mathrm{vw}}$.

Oil recovery efficiency can be called field oil efficiency (FOE) and oil saturation at the end of surfactant flood $S_{\text {orc }}$ can be written as saturation at present $S_{0}$. So Eq. (11) becomes

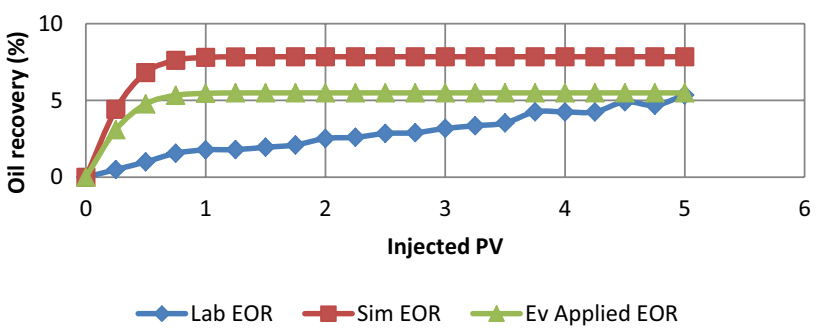

Fig. 2 Tertiary oil recovery observed after bio-surfactant and butanol injection in Eclipse, modified Eclipse and laboratory

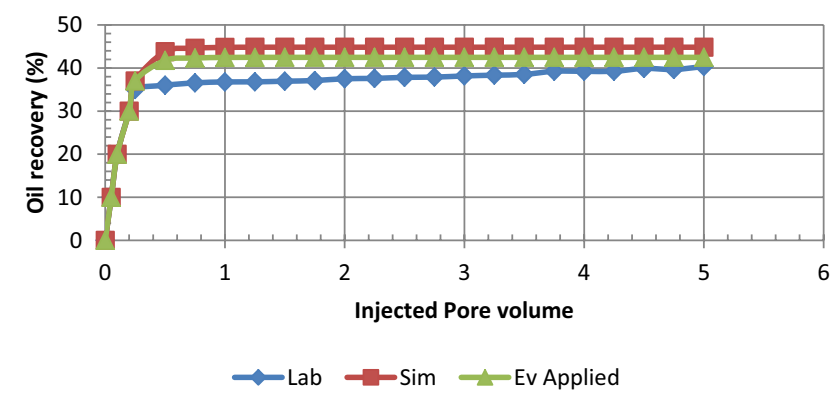

Fig. 3 Total oil recovery observed after water bio-surfactant and butanol injection in Eclipse, Modified Eclipse, and laboratory

$\mathrm{FOE}=\frac{N_{\mathrm{P}}}{N}=\frac{\left(S_{\mathrm{oi}}-S_{\mathrm{o}}\right)}{\left(S_{\mathrm{oi}}\right)} \times E_{\mathrm{vw}}$.

The FOE Eq. (14) provided in Eclipse did not include a volumetric sweep, so Eq. (20), derived by Green and Willhite (1998), was included to give a better match.

\section{Modification implementation in Eclipse}

The first modification was implemented by making the IFT table a function of the surfactant and alcohol concentration; from there, the concentration of the surfactant and alcohol mixture was solved using the conservation equation. The rest of the steps were followed by the Eclipse solver.

To implement modification two, first FOE was calculated in Eclipse and put into an Excel sheet. Then $E_{\mathrm{vw}}$ was calculated based on laboratory data. At the end, FOE value was multiplied by $E_{\mathrm{vw}}$ and put into a different column. Injected PV versus different FOE curves were plotted and compared with laboratory data. Figure 2 shows the implementation of modification, showing that after Ev was applied the EOR curve came closer to laboratory EOR than a normal sim curve. A similar characteristic may be observed in the total recovery plot in Fig. 3. 


\section{Simulation of core-flood experiments}

The three green surfactant core floods were simulated; simulation and experimental results were then compared. Simulation basics and input variables are explained below.

\section{Core-flood simulation basics}

First, the core is divided into a number of cells, and basic data are provided for each one. Then injection and production wells are positioned with the cells. The required well production or injection rates are specified as functions of time. Finally the equations are solved to give the pressure and saturation for each block as well as the production of each phase from each well.

\section{Input parameters}

The simulation model was developed using the block-cantered geometry option, which has the shape of flat-lying "sugar-cubes" arranged in a three-dimensional volume comprising one geological layer with ten columns of cells in the lateral direction and one column of cells in the transverse direction (i.e., $10 \times 1 \times 1$ ). A rectangular core block is presented in Fig. 4. The main reason for using this geometry is because block-cantered grids tend to be geometrically simpler, thus helping to avoid any unexpected error and confusion when designing the ECLIPSE simulation file. However, this geometry is still considered highly reliable in representing real field conditions while providing precise results in reservoir simulations.

In the laboratory the core-flood experiments were done using cylindrical cores of Berea sandstone, but in simulation a rectangular core model was taken, keeping the same volume as the cylindrical core. Below is the mathematical evidence that volume was kept the same in both shapes:

Core length $=8.126 \mathrm{~cm}$

Diameter $=3.85 \mathrm{~cm}$

Cylindrical core:

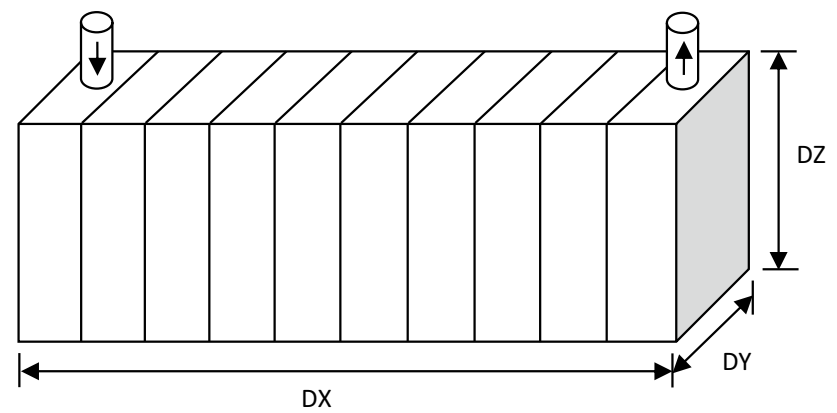

Fig. 4 Rectangular core block $(10 \times 1 \times 1)$
Cross sectional area $=\Pi D^{2} / 4=11.64156 \mathrm{~cm}^{2}=3.412 \mathrm{c}$ $\mathrm{m} \times 3.412 \mathrm{~cm}$

Volume $=\Pi D^{2} / 4 \times L=11.64156 \mathrm{~cm}^{2} \times 8.126 \mathrm{~cm}=$ $94.6 \mathrm{~cm} 3$

Rectangular core:

$\mathrm{DY}=\mathrm{DZ}=3.412 \mathrm{~cm}$

Length $=\mathrm{DX}=8.126 \mathrm{~cm}$

Cross sectional area $=\mathrm{DY} \times \mathrm{DZ}=3.412 \mathrm{~cm} \times 3.412 \mathrm{~cm}=$ $11.64156 \mathrm{~cm}^{2}$

Volume $=\mathrm{DY} \times \mathrm{DZ} \times \mathrm{L}=\mathrm{DY} \times \mathrm{DZ} \times \mathrm{DX}=11.64156 \mathrm{~cm}^{2}$ $\times 8.126 \mathrm{~cm}=94.6 \mathrm{~cm}^{3}$

In the laboratory, stag oil was used to do the core flooding. To replicate the laboratory conditions, the stag reservoir depth was taken for the simulation. The reservoir of interest was $680 \mathrm{~m}$ below ground level and had one geological layer, represented by the grid block. The grid block thickness was $3.412 \mathrm{~cm}$. The rectangular size of the reservoir model was $3.412 \mathrm{~cm}$ wide by $8.126 \mathrm{~cm}$ long, represented by ten columns of cells in the lateral direction and one column of cells in the transverse direction.

This simulation considers only one injection well and a single production well. These two wells were located at separate corners at the edge of the core model. This position gave the clearest view of the direction of the surfactant slug, which was expected to flow from the injection well to the production well, sweeping the residual oil in the reservoir before it. Both wells were perforated throughout their core thickness with a wellbore diameter of $4 \mathrm{~mm}$.

The reservoir properties used to simulate the effect of surfactants on EOR are based on a medium-wet, undersaturated reservoir. It is assumed that only two phases of fluid exist in the reservoir system: oil and water aquifer. The water phase is considered to have zero brine salinity; thus the injected surfactants in this simulation process are not influenced by any ionic interaction with a brine environment.

All three data files use the same reservoir parameters and physical grid dimensions, tabulated in Table 1. The only variable is in the surfactant and alcohol mixture (i.e., viscosity, capillary number, surface tension, etc.); the waterflood data file has zero surfactant properties. Tables 2, 3, 4, 5, 6, 7, 8,9 and 10 present the input data for the three formulations

Table 1 Reservoir and simulation model properties

\begin{tabular}{ll}
\hline Model physical dimension & $8.126 \mathrm{~cm} \times 3.412 \mathrm{~cm} \times 3.412 \mathrm{~cm}$ \\
Datum pressure & $72.41 \mathrm{bar}=1050 \mathrm{psi}$ \\
Datum depth & $680 \mathrm{~m}$ \\
Depth at oil-water contact & $690 \mathrm{~m}$ \\
Porosity, $\Phi$ & 0.20 \\
Horizontal permeability, $k_{\mathrm{h}}$ & Top layer: $470 \mathrm{mD}$ \\
Vertical permeability, $k_{\mathrm{v}}$ & Top layer: $470 \mathrm{mD}$ \\
Well/tube diameter $(\mathrm{mm})$ & 4.00 \\
\hline
\end{tabular}

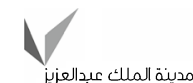

KACST مدينة الملكن Springer 
Table 2 Relative permeability and saturation table of formulation 1 (bio-surfactant and butanol)

\begin{tabular}{llll}
\hline$S_{\mathrm{w}}$ & $K_{\mathrm{rw}}$ & $K_{\mathrm{ro}}$ & $S_{\mathrm{o}}$ \\
\hline 0.18 & 0.0015 & 0.67 & 0.82 \\
0.2 & 0.003 & 0.64 & 0.8 \\
0.22 & 0.006 & 0.61 & 0.78 \\
0.24 & 0.009 & 0.58 & 0.76 \\
0.29 & 0.02 & 0.51 & 0.71 \\
0.39 & 0.06 & 0.37 & 0.61 \\
0.49 & 0.13 & 0.24 & 0.51 \\
0.54 & 0.16 & 0.19 & 0.46 \\
\hline
\end{tabular}

Table 3 Fluid property data of formulation 1 (bio-surfactant and butanol)

\begin{tabular}{ll}
\hline Oil density $\left(\mathrm{kg} / \mathrm{m}^{3}\right)$ & 936 \\
Water density $\left(\mathrm{kg} / \mathrm{m}^{3}\right)$ & 1000 \\
Oil viscosity $(\mathrm{cP})$ & 0.47 \\
Water viscosity $(\mathrm{cP})$ & 0.34 \\
Adsorption function & 0.00002 \\
Initial IFT $($ dyne/cm) & 27 \\
Final IFT $($ dyne/cm) & 1.8 \\
Liquid rate $(\mathrm{cc} / \mathrm{min})$ & 100 \\
Volumetric sweep efficiency & 0.70 \\
\hline
\end{tabular}

of the models. Tables 2, 5 and 7 are generated by Eclipse based on three water saturations: initial, at the end of waterflood, and at the end of surfactant flood. Tables 3, 6 and 8 are fluid property data of three formulations. Viscosity and IFT are calculated in the lab and liquid rate is recorded at time of experiment. IFT values at different surfactant and co-surfactant concentrations are tabled in Tables 4, 7 and 10.

$E_{\mathrm{vw}}$ was calculated using Eq. (22). Free gas saturation $\left(S_{\mathrm{g}}\right)$ was assumed to be zero as core was evaluated and dissolved oxygen was removed from brine. Formation volume factor and average water saturation were assumed within the estimation technique because core-flood instrument was broken down at middle of the experiment. Required data for calculating those values were not monitored due to that incident. $N_{\mathrm{p}}, S_{\mathrm{o}}, S_{\mathrm{wc}}$, and $V_{\mathrm{p}}$ were taken from Core-flooding experiments and were used to measure $E_{\mathrm{vw}} \cdot E_{\mathrm{vw}}$ values of
Table 5 Relative permeability and saturation table of formulation 2 (APG 264 and butanol)

Table 6 Fluid property data of formulation 2 (APG 264 and butanol)

\begin{tabular}{ll}
\hline Oil density $\left(\mathrm{kg} / \mathrm{m}^{3}\right)$ & 936 \\
Water density $\left(\mathrm{kg} / \mathrm{m}^{3}\right)$ & 1000 \\
Oil viscosity $(\mathrm{cP})$ & 0.47 \\
Water viscosity $(\mathrm{cP})$ & 0.34 \\
Adsorption function & 0.00002 \\
Initial IFT (dyne/cm) & 27 \\
Final IFT (dyne/cm) & 0.55 \\
Well/tube diameter $(\mathrm{mm})$ & 4.00 \\
Liquid rate (cc/min) & 100 \\
Volumetric sweep efficiency & 1.00 \\
\hline
\end{tabular}

three formulations were presented in Tables 3, 6 and 8. The Mathematical development of volumetric sweep efficiency is presented in "Appendix A".

\section{Results and discussion}

Three green surfactant floods were simulated and the results compared with laboratory core-flooding data to verify simulation accuracy. JF-2 bio-surfactant from anionic green surfactants with butanol as a co-surfactant mixture was the model in first formulation. The second formulation was a nonionic surfactant APG and butanol mixture. Last was a mixture of anionic and nonionic surfactants with a

\begin{tabular}{llll}
\hline$S_{\mathrm{w}}$ & $K_{\mathrm{rw}}$ & $K_{\text {ro }}$ & $S_{\mathrm{o}}$ \\
\hline 0.22 & 0.00 & 0.61 & 0.78 \\
0.24 & 0.00 & 0.58 & 0.76 \\
0.29 & 0.02 & 0.51 & 0.71 \\
0.39 & 0.06 & 0.37 & 0.61 \\
0.54 & 0.16 & 0.19 & 0.46 \\
0.64 & 0.24 & 0.11 & 0.37 \\
0.70 & 0.32 & 0.05 & 0.30 \\
0.80 & 0.50 & 0.01 & 0.20 \\
0.86 & 0.63 & 0.00 & 0.14 \\
\hline
\end{tabular}

Table 4 Surfactant concentration, IFT, viscosity, and adsorption data of formulation 1 (bio-surfactant and butanol)

\begin{tabular}{llll}
\hline $\begin{array}{l}\text { Surfactant and alcohol concen- } \\
\text { tration }(\mathrm{mg} / \mathrm{l})\end{array}$ & IFT $($ dyne/cm) & Viscosity $(\mathrm{cP})$ & Adsorption function \\
\hline 0 & 27 & 0.34 & 0.00000 \\
5010 & 2.2230 & 0.34 & 0.00002 \\
5020 & 1.8330 & 0.34 & 0.00002 \\
5030 & 1.8520 & 0.34 & 0.00002 \\
5040 & 1.7870 & 0.34 & 0.00002 \\
5050 & 1.8350 & 0.34 & 0.00002 \\
5060 & 1.7730 & 0.34 & 0.00002 \\
\hline
\end{tabular}


Table 7 Surfactant concentration, IFT, viscosity, and adsorption data of formulation 1 (APG 264 and butanol)

\begin{tabular}{llll}
\hline $\begin{array}{l}\text { Surfactant and alcohol concen- } \\
\text { tration }(\mathrm{mg} / \mathrm{l})\end{array}$ & IFT (dyne/cm) & Viscosity $(\mathrm{cP})$ & Adsorption function \\
\hline 0 & 27 & 0.34 & 0.00000 \\
9045 & 0.4060 & 0.34 & 0.00002 \\
13,045 & 0.3960 & 0.34 & 0.00002 \\
17,045 & 0.3520 & 0.34 & 0.00002 \\
21,045 & 0.3790 & 0.34 & 0.00002 \\
\hline
\end{tabular}

Table 8 Relative permeability and saturation table of formulation 3 (APG 264, biosurfactant and butanol)

\begin{tabular}{llll}
\hline$S_{\mathrm{w}}$ & $K_{\text {rw }}$ & $K_{\text {ro }}$ & $S_{\text {o }}$ \\
\hline 0.17 & 0.00 & 0.68 & 0.83 \\
0.18 & 0.00 & 0.67 & 0.82 \\
0.20 & 0.00 & 0.64 & 0.80 \\
0.22 & 0.01 & 0.61 & 0.78 \\
0.24 & 0.01 & 0.58 & 0.76 \\
0.29 & 0.02 & 0.51 & 0.71 \\
0.39 & 0.06 & 0.37 & 0.61 \\
0.49 & 0.13 & 0.24 & 0.51 \\
0.54 & 0.16 & 0.19 & 0.46 \\
0.57 & 0.18 & 0.16 & 0.43 \\
0.64 & 0.24 & 0.11 & 0.37 \\
0.70 & 0.32 & 0.05 & 0.30 \\
\hline
\end{tabular}

Table 9 Fluid property data of formulation 3 (APG 264, bio-surfactant and butanol)

\begin{tabular}{ll}
\hline Oil density $\left(\mathrm{kg} / \mathrm{m}^{3}\right)$ & 936 \\
Water density $\left(\mathrm{kg} / \mathrm{m}^{3}\right)$ & 1000 \\
Oil viscosity $(\mathrm{cP})$ & 0.47 \\
Water viscosity $(\mathrm{cP})$ & 0.34 \\
Adsorption function & 0.00002 \\
Initial IFT $($ dyne/cm) & 27 \\
Final IFT $($ dyne/cm) & 0.41 \\
Liquid rate $(\mathrm{cc} / \mathrm{min})$ & 100 \\
Volumetric sweep efficiency & 1.00 \\
\hline
\end{tabular}

co-surfactant; in this case, APG and JF-2 bio-surfactant blended with butanol. In all three cases, secondary recovery (oil recovery due to water injection) and tertiary recovery (oil recovery due to surfactant and co-surfactant injection) were studied; results are shown in figures below.

\section{Formulation 1: bio-surfactant, butanol and water}

A JF-2 bio-surfactant and butanol mixture was the model in this formulation. First fresh water was injected into the core model and then surfactant solutions were injected to see the effect of secondary and tertiary recoveries.

\section{Saturation effect}

The simulated oil saturation profile after 4 PV of waterflooding was compared with the laboratory waterflood data. The input data for the simulation are listed in Tables 2 and 3; the two solutions are compared in Fig. 5. The simulation result closely matched the laboratory data apart from the section from 0.8 to $2.2 \mathrm{PV}$; this anomaly is due to the simulation input parameter not being properly adjusted. However, there is a perfect match between 2.4 and $5 \mathrm{PV}$.

There was a 0.31 decrease in oil saturation from 0.82 to 0.51 in the laboratory. To see the other ionic effects in the mixture, salinity was assumed to be zero in simulation. Fresh water was introduced via the injection well. The average oil
Table 10 Surfactant concentration, IFT, viscosity, and adsorption data of formulation 1 (APG 264, biosurfactant and butanol)

\begin{tabular}{llll}
\hline $\begin{array}{l}\text { Surfactant and alcohol concen- } \\
\text { tration }(\mathrm{mg} / \mathrm{l})\end{array}$ & IFT (dyne/cm) & Viscosity $(\mathrm{cP})$ & Adsorption function \\
\hline 0 & 27 & 0.34 & 0.00000 \\
10 & 2.2230 & 0.34 & 0.00002 \\
20 & 1.8330 & 0.34 & 0.00002 \\
30 & 1.8520 & 0.34 & 0.00002 \\
40 & 1.7870 & 0.34 & 0.00002 \\
50 & 1.8350 & 0.34 & 0.00002 \\
60 & 1.7730 & 0.34 & 0.00002 \\
\hline
\end{tabular}




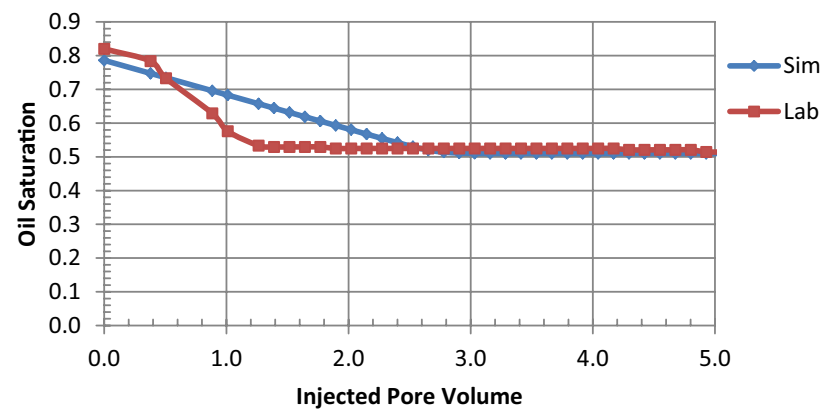

Fig. 5 Average oil saturation observed in laboratory and simulation after water injection

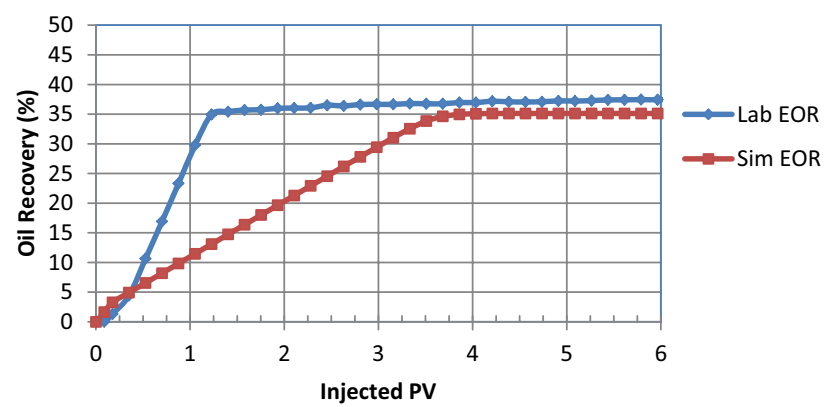

Fig. 6 Secondary oil recovery observed in laboratory and simulation after brine injection

saturation reduced from 0.79 to 0.51 each grid block, indicating that oil had been displaced.

\section{Secondary oil recovery}

The $2 \% \mathrm{NaCl}$ water was injected into a core at a rate of $0.0024 \mathrm{~m}^{3} /$ day until no oil was produced from the core. In the simulation fresh water was introduced via the injection well at a rate of $0.0024 \mathrm{~m}^{3} /$ day. The simulation input data are listed in Tables 2 and 3; oil recovery is plotted in Fig. 6. About 35\% oil was recovered; in the laboratory about $37 \%$ oil was recovered. The $2 \%$ higher value is because in the laboratory $2 \% \mathrm{NaCl}$ was used but in simulation fresh water was used.

The simulated oil recovery curve does not match the laboratory curve from 0.4 to $3.2 \mathrm{PV}$ because the simulation input parameter was not properly adjusted. However, there is a good match between 3.4 and 5 PV.

\section{Tertiary oil recovery}

Bacillus mojavensis strain JF-2 bio-surfactant, commonly called JF-2 bio-surfactant, is used in tertiary oil recovery. A solution of $45 \mathrm{mg} / \mathrm{l} \mathrm{JF}-2$ bio-surfactant and $0.5 \%$ butanol was injected into the core to investigate the volume of oil

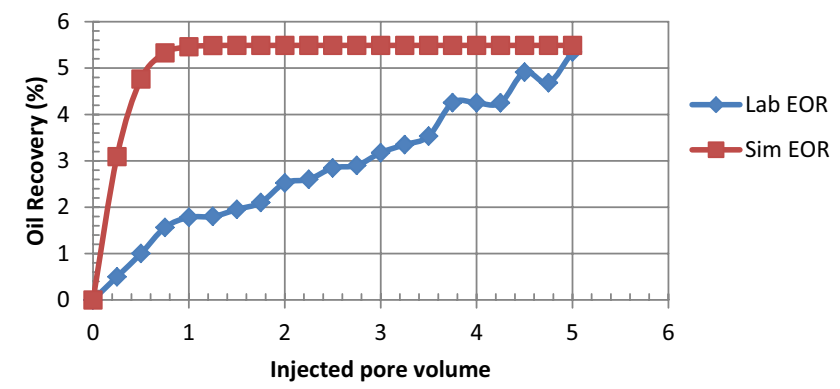

Fig. 7 Tertiary oil recovery observed in laboratory and simulation after bio-surfactant and butanol injection

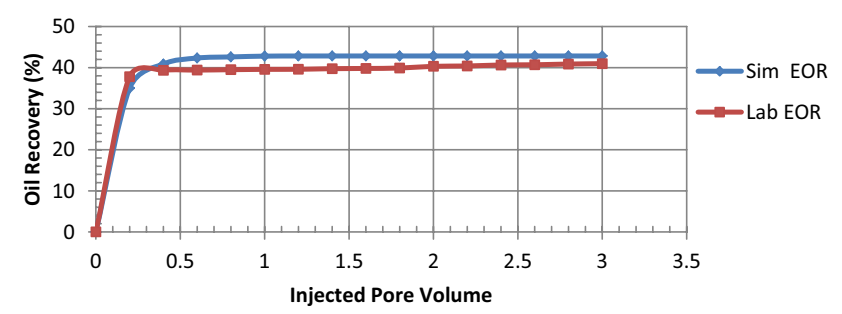

Fig. 8 Total oil recovery observed in laboratory and simulation after brine, and bio-surfactant and butanol injection

recovery with a bio-surfactant/butanol solution. Input data appear in Tables 2 and 3; oil recovery is plotted in Fig. 7. A higher oil recovery is achieved in simulation than in the laboratory core flood. TOR is about $7.8 \%$ in the simulation study, and about $5.4 \%$ in the laboratory. Neither of these values is significant compared with other TOR values. Oil production started earlier in the simulation and reached $7.8 \%$ with $1 \mathrm{PV}$ injection of solution, and remained the same when the injected volume was increased. In the laboratory, the oil production curve rose slowly with an increase of injected volume and reached its highest point of $5.4 \%$ with $5 \mathrm{PV}$.

\section{Total oil recovery}

First water, then a bio-surfactant/butanol solution, were injected into the core model, and total oil production was examined. Total recovery profiles of simulation and laboratory are compared in Fig. 8, which shows that total recoveries were $41 \%$ in simulation and $40 \%$ in laboratory core flooding. The results suggest that a bio-surfactant/butanol solution is most likely too weak to mobilize residual oil. The simulation oil recovery profile showed that oil recovery did increase with an increase of surfactant/co-surfactant.

\section{Formulation 2: APG, butanol and water}

In the second preparation nonionic surfactant APG and butanol were combined and then passed through the core.

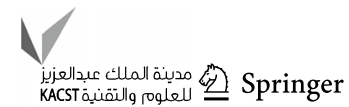


Results were examined and compared with laboratory data to determine oil recovery.

\section{Saturation effect}

The simulated oil saturation plot of waterflood was compared with laboratory data to verify the model in Fig. 9. Input data for the simulation are listed in Tables 4 and 5 .

There was a good match at the early and later stages of these curves, except between 1 and 3 PV. This indicates that the simulation gave better results. Simulated oil saturation decreased from 0.78 to 0.47 in $3 \mathrm{PV}$ injection of water and then became constant. There was a 0.29 reduction in oil saturation in the laboratory between 0.78 and 0.49 in $1.8 \mathrm{PV}$; after that saturation remained unchanged.

\section{Secondary oil recovery}

In the simulation fresh water was introduced via the injection well at a rate of $0.0024 \mathrm{~m}^{3} /$ day. The simulation input data are listed in Tables 4 and 5; output is plotted in Fig. 10. About $41 \%$ oil was recovered; in the laboratory about $40 \%$ was recovered.

The simulated cumulative oil recovery curve went up slowly from 0 to $41 \%$ between 0 and $5 \mathrm{PV}$, then remained constant (steady state). The laboratory cumulative oil recovery curve reached $37 \%$ at $1.8 \mathrm{PV}$ injection of brine. It produced more oil than the simulation at $1.8 \mathrm{PV}$ injection, which reached only about $14 \%$.

The simulated oil recovery curve does not match the laboratory curve from 0.5 to $3.2 \mathrm{PV}$. This is because the simulation input parameter was not properly adjusted. However, there was a perfect match from $5 \mathrm{PV}$ onward.

\section{Tertiary oil recovery}

A combination of $0.5 \%$ APG and $0.5 \%$ Butanol was mixed with fresh water and injected into the core model. Input data are provided in Tables 4 and 5. Cumulative oil recovery with

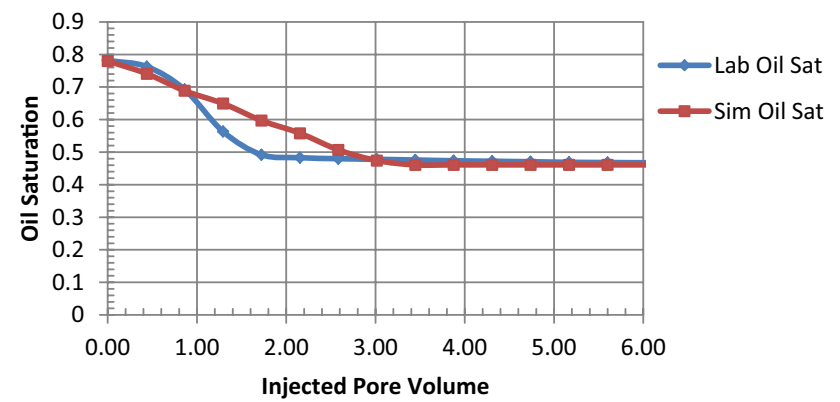

Fig. 9 Average oil saturation observed in laboratory and simulation after brine injection

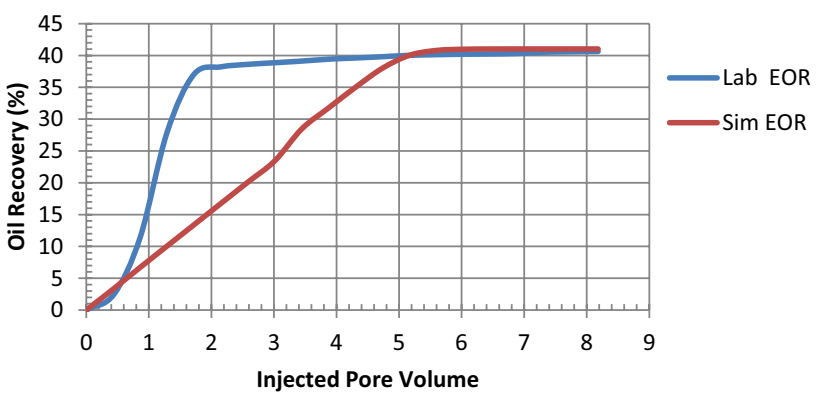

Fig. 10 Secondary oil recovery observed in laboratory and simulation after brine injection

a surfactant solution was investigated. As shown in Fig. 11, $41 \%$ tertiary oil was recovered with an injection of $2 \mathrm{PV}$ surfactant solution. The same amount of oil was recovered in laboratory core flooding with a $2 \mathrm{PV}$ injection of surfactant solution. The simulated curve differed from the laboratory curve between 0 and $1 \mathrm{PV}$ but became closer at the later stage; at the end they matched. These results suggest that this formulation is more active than a bio-surfactant solution.

\section{Total oil recovery}

Total cumulative oil recovery by APG and butanol solution was examined and compared with laboratory core-flooding data. Recovery curves from both methods are plotted in Fig. 12; the curves match. In the simulation $81 \%$ total oil was recovered, and in the laboratory $82 \%$.

\section{Formulation 3: APG, bio-surfactant butanol and water}

This formulation was a mixture of anionic and nonionic surfactants with a co-surfactant. In this preparation APG and JF-2 bio-surfactant were blended with butanol. APG, bio-surfactant, butanol and brine, and core properties were discussed in "Model description".

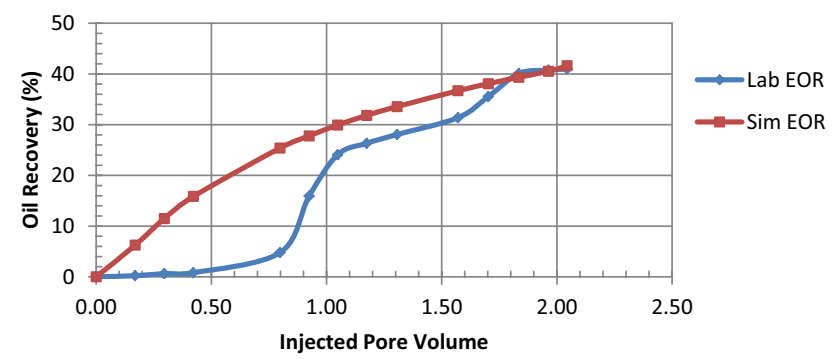

Fig. 11 Tertiary oil recovery observed in laboratory and simulation after APG 264 and butanol injection 


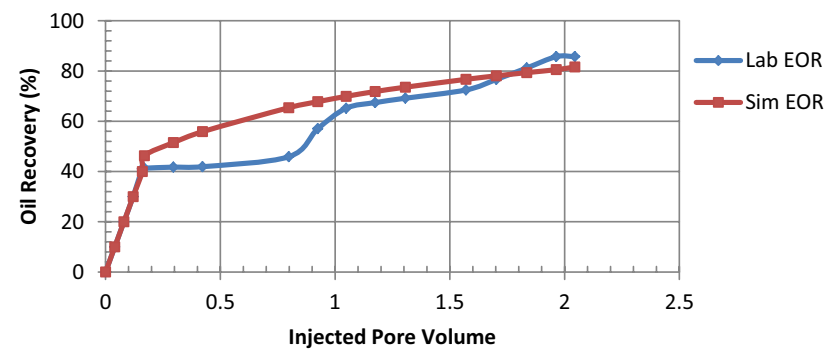

Fig. 12 Total (secondary and tertiary) oil recovery observed in laboratory and simulation after brine, APG 264 and butanol injection

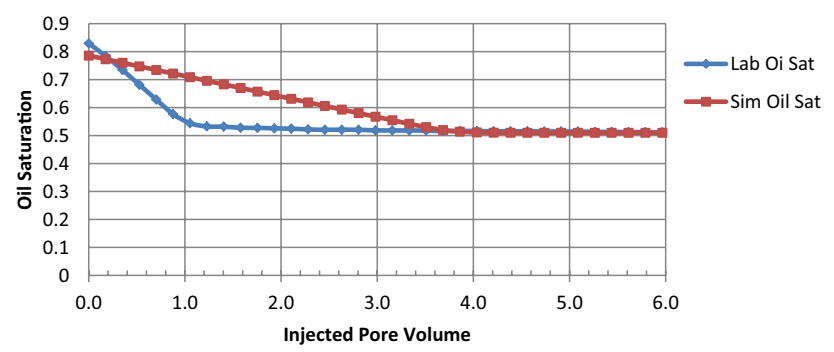

Fig. 13 Average oil saturation observed in laboratory and simulation after brine injection

\section{Saturation effect}

The saturation effect of the injection volume of water and surfactant was studied. The simulated oil profile was evaluated against the laboratory oil saturation. Input data for the simulation are listed in Tables 6 and 7; the two solutions are plotted in Fig. 13.

Average oil saturation dropped gradually from 0.79 to 0.5 in $4 \mathrm{PV}$ injection of water in simulation, then remained steady. Oil production started as saturation went down with the injection of $4 \mathrm{PV}$ water; after that oil production stayed constant. This indicates that the injection of water was effective up to $4 \mathrm{PV}$ and then had no further effect injection on production. A similar pattern of oil saturation was monitored in core flooding, with a swift fall from 0.83 to 0.53 with 1.2 PV injection. After that it became stable. There was no good match between the two curves from 0.4 and 3.6 PV because of a poor simulator input adjustment.

\section{Secondary oil recovery}

Secondary oil recovery curves of both simulation and laboratory are plotted in Fig. 14; Simulation input data are presented in Tables 6 and 7. Fresh water was introduced into the core model through the injection well at a rate of $0.0024 \mathrm{~m}^{3} /$ day until oil production became stable. During this time, from 0 to $2.5 \mathrm{PV}$, oil production increased from 0 to $35 \%$ of

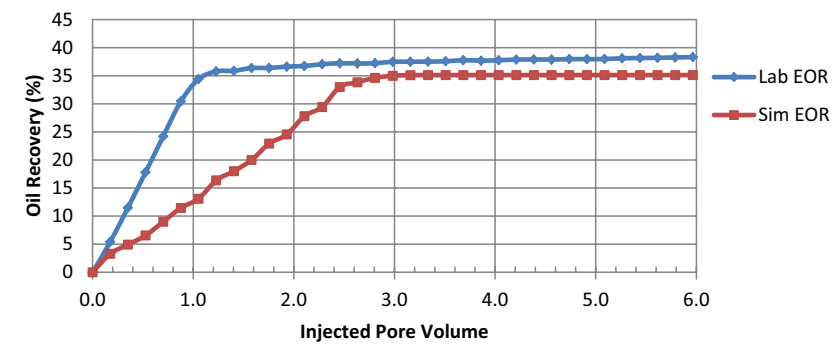

Fig. 14 Secondary oil recovery observed in laboratory and simulation after brine injection

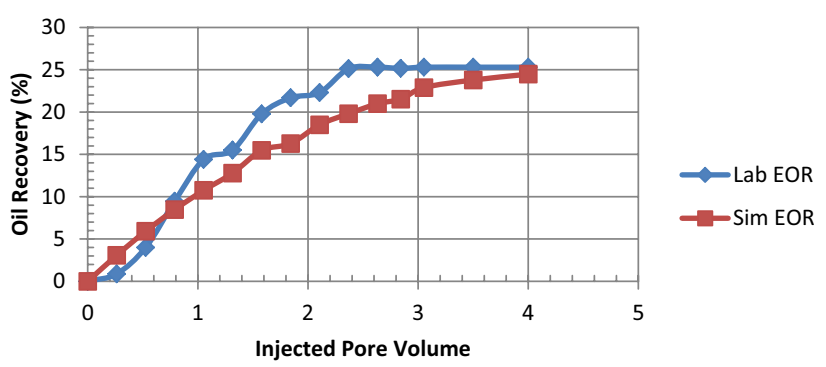

Fig. 15 Tertiary oil recovery observed in laboratory and simulation after APG 264, bio-surfactant and butanol injection

original oil in place. There was steady oil production after 2.5 PV injection. In the laboratory there was a rapid increase in oil production to $35 \%$ with $1 \mathrm{PV}$ injection, followed by a $2 \%$ rise from $35 \%$ to $37 \%$ in $5 \mathrm{PV}$.

There was a $2 \%$ difference in cumulative oil recovery between the two methods.

\section{Tertiary recovery}

This simulation test explored the effect of anionic and nonionic blends with alcohol on cumulative tertiary oil recovery. An APG, bio-surfactant and butanol combination solution was passed into the model core at a rate of $100 \mathrm{cc} / \mathrm{h}$. The cumulative tertiary oil recovery is plotted in Fig. 15 and Tables 6 and 7 show the input data. Nearly $25 \%$ of oil was recovered when $4 \mathrm{PV}$ of surfactant solution was injected. Oil production went up gradually to $10 \%, 17 \%$, and $22 \%$ with 1 $\mathrm{PV}, 2 \mathrm{PV}$, and $3 \mathrm{PV}$ injections, respectively. However, in the laboratory there was a $25 \%$ rise of cumulative oil with 2.4 $\mathrm{PV}$ of injection. Oil recovery rose to about $13 \%, 22 \%$, and $25 \%$ in $1 \mathrm{PV}, 2 \mathrm{PV}$, and $3 \mathrm{PV}$ injections, respectively. Results from both methods reveal that an APG and bio-surfactant solution is a promising green surfactant which has a capability to recover substantial tertiary oil.

Total oil recovery This simulation investigated the impact of a solution of water and surfactants on total oil recovery. First

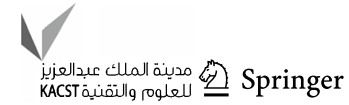


water and then an APG, bio-surfactant and butanol solution were injected into the core model. Total cumulative oil production was examined and compared with the laboratory results; total simulated and core-flooded oil recovery curves are plotted in Fig. 16. About $60 \%$ cumulative oil recovery was found in simulation, and about $64 \%$ in core flooding. The results from both methods suggest that an APG, biosurfactant and butanol solution is very likely to mobilize a considerable amount of residual oil.

Simulated secondary recovery results in Figs. 6, 10 and 14 are poorly matched with those of experimental. It would be most likely because of (1) using constant values such as viscosity and adsorption, (2) higher flow rate with respect to field rate, (3) generated permeability table using Stone II model. However, tertiary oil recovery curves are close to laboratory values.

This study includes only oil recovery potential of surfactant formulation because the main objective is to modify eclipse to examine the combined effect of surfactant and alcohol in enhanced oil recovery as surfactant and alcohol are microbial by-products and they work together in increasing recovery. In addition, it would be easier to tackle simple issue at the early stage of the project.

\section{Conclusion}

1. The modified Eclipse simulator simulated the effect of secondary and tertiary oil recovery, using water with a green surfactant and alcohol solution, and with a solution of anionic and nonionic surfactants blended with alcohol. These features were tested by core-flood experiments.

2. A core-flood experiment using bio-surfactant and alcohol on a Berea sandstone core was simulated. Simulated results were higher than experimental results but compared reasonably. The GEOR model could be used to simulate the effect of bio-surfactant and bio-alcohol on MEOR.

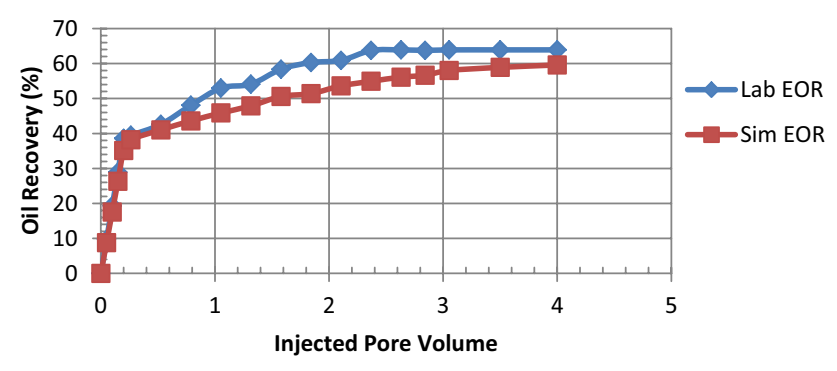

Fig. 16 Total (secondary and tertiary) oil recovery observed in laboratory and simulation after brine, APG 264, bio-surfactant and butanol injection
3. The simulated tertiary and total oil recoveries of a blended APG and butanol solution were compared with experimental values. Simulated TOR and total recovery were $41 \%$ and $81 \%$, respectively, while core-flooding TOR and total recovery were $41 \%$ and $82 \%$, respectively.

4. A simulated core-flood experiment using an APG, biosurfactant and butanol combination returned simulated outputs with a reasonable match to experimental results. TOR and total recovery values from the simulation were $25 \%$ and $60 \%$.

\section{Recommendations}

1. A brine treacle model should be included in simulations to examine the effect of brine salinity on oil recovery.

2. Overburden pressure should be included to see the effect on rock compaction.

3. Microbial reaction should be included in the EOR model to see the real microbial oil recovery.

4. A cylindrical core model should used in place of a rectangular core model to replicate the core.

Acknowledgements The authors thank King Fahd University of Petroleum and Minerals (KFUPM), The University of Western Australia (UWA), Commonwealth Scientific Industrial Research Organization (CSIRO), Schlumberger SIS, Australia, and BASF for the research support of this study.

Open Access This article is distributed under the terms of the Creative Commons Attribution 4.0 International License (http://creativeco mmons.org/licenses/by/4.0/), which permits unrestricted use, distribution, and reproduction in any medium, provided you give appropriate credit to the original author(s) and the source, provide a link to the Creative Commons license, and indicate if changes were made.

\section{Appendix A: Equations for Eclipse}

\section{A1: Stone II relative permeability model}

Eclipse has the option to use either the Stone II three phase relative permeability models or the default model in the surfactant relative permeability model. In this study Stone II three phase relative permeability model was used. Stone II three phase relative permeability model is given below:

$k_{\mathrm{ro}}=\left(k_{\mathrm{ro}}\right)_{S_{\mathrm{wc}}}\left[\left(\frac{k_{\mathrm{row}}}{\left(k_{\mathrm{ro}}\right)_{S_{\mathrm{wc}}}}+k_{\mathrm{rw}}\right)\left(\frac{k_{\mathrm{rog}}}{\left(k_{\mathrm{ro}}\right)_{S_{\mathrm{wc}}}}+k_{\mathrm{rg}}\right)-\left(k_{\mathrm{rw}}+k_{\mathrm{rg}}\right)\right]$,

where $k_{\mathrm{ro}}=$ relative permeability of oil, $k_{\mathrm{rg}}=$ relative permeability of gas, $k_{\mathrm{rw}}=$ relative permeability of water, $\left(k_{\mathrm{ro}}\right)_{S_{\mathrm{wc}}}=$ relative permeability of oil at $S_{\mathrm{wc},} k_{\text {row }}=$ oil relative 
permeability as determined from the oil-water two-phase relative permeability at $S_{\mathrm{w},} k_{\mathrm{rog}}=$ oil relative permeability as determined from the gas-oil two-phase relative permeability at $S_{\mathrm{g},} S_{\mathrm{wc}}=$ connate water saturation.

\section{A2: Mathematical development of volumetric sweep efficiency}

The technique for estimating volumetric sweep efficiency is applicable in those reservoirs in which the waterflood is initiated when reservoir pressure is above or below the initial bubble point pressure (Cob and Marek 1997). The method is applicable for five spot and regular or irregular pattern waterfloods. The assumptions of the technique are (1) the gas fillup has been achieved in all layers and (2) the oil remaining within the reservoir is located in the water swept portion of the reservoir or the oil bank portion of the reservoir. Using these assumptions, the final form of the equation for computing volumetric sweep efficiency $\left(E_{\mathrm{vW}}\right)$ becomes

$E_{\mathrm{vw}}=\frac{\frac{N_{\mathrm{p}} B_{\mathrm{o}}}{V_{\mathrm{p}}}+S_{\mathrm{g}}}{\overline{S_{\mathrm{w}}}-S_{\mathrm{wc}}}$,

where $N_{\mathrm{p}}=$ oil production since start of waterflooding, $S_{\mathrm{g}}=$ free gas saturation, $S_{\mathrm{o}}=$ oil saturation, $S_{\mathrm{wc}}=$ connect water saturation at start of waterflood, $V_{\mathrm{p}}=$ floodable pore volume, $\overline{S_{\mathrm{w}}}=$ average water saturation in the water swept portion of the pore volume, $B_{\mathrm{o}}=$ formation volume factor of oil.

Volumetric sweep efficiency can be calculated using Eq. (22) when oil production parameters are known. Average water saturation can be obtained from fractional flow analysis.

\section{References}

Bedrikovetsky P, Muhammad AW, Chang G, Souza ALS, Furtado C (2009) Taking advantage of injectivity decline for sweep enhancing during waterflood with horizontal wells. In: Proceedings of the
2009 SPE European formation damage conference, Scheveningen, SPE 122844. https://doi.org/10.2118/122844-MS

Cob WM, Marek FJ (1997) Determination of volumetric sweep efficiency in mature waterfloods using production data. In: Proceedings of the 1997 SPE annual technical conference and exhibition, San Antonio, Texas, USA, SPE 38902-MS

Dongu AH, Mitsuishi H, Yamamoto RH (1984) Numerical simulation of micellar polymer field processes. In: Proceedings of the SPE annual technical conference, Houston, TX, SPE 113121

Gjerde O, Jarosch HS, Kaarstad T (1988) Improvement to the black oil simulator, SPE 18612. Available from: SPEelibrary [1989]

Green DW, Willhite GP (1998) Enhanced oil recovery. SPE, Texas

Kumar R, Shrivastava SK (2000) Effect of gas relative permeability and mobility ration in reservoir simulation using different methods. In: Proceedings of the 2000 SPE Asia Pacific oil and gas conference and exhibition, Brisbane, SPE 64423. https://doi. org/10.2118/64423-MS

Nelson RC (1983) The effect of live crude on phase behaviour and oilrecovery efficiency of surfactant flood systems. SPE J 23(3):501510. https://doi.org/10.2118/10677-PA

Salimi H, Bruining J (2008) Improved prediction of oil recovery from waterflooding fractured reservoirs. In: Proceedings of the 2008 SPE annual technical conference and exhibition, Denver, Colorado, USA, SPE 115361. https://doi.org/10.2118/115361-PA

Schlumberger (2017) ECLIPSE technical description manual

Shabani-Afrapoli M, Crescente C, Li S, Alipour S, Torsaeter O (2012) Simulation study of displacement mechanisms in microbial improved oil recovery experiment. In: Proceedings of the SPE EOR conference at oil and gas West Asia, Muscat, SPE 153323

Tiamiyu OM, Boukadi F (2011) Experimental and simulation study on use of surfactant and de-emulsifier blend additives in steam flood as EOR technique in heavy oil reservoir. In: Proceedings of the SPE middle east oil and gas show and conference, Manama, SPE 139582

Todd MR, Chase CA (1979) A numerical simulation for predicting chemical flood performance. In: Proceedings of the SPE reservoir simulation symposium, Denver, CO, SPE 7689

Yu SY, Akervoll I, Torsaeter O, Stensen JA, Kleppe J, Midtlyng SH (1998) History matching gas injection processes with in-situ saturation measurements and process hysteresis. In: Proceedings of the 1998 SPE international conference and exhibition, Beijing, China, SPE 48842. https://doi.org/10.2118/48842-MS

Publisher's Note Springer Nature remains neutral with regard to jurisdictional claims in published maps and institutional affiliations. 